\title{
Fabrication and characterization of spectrally selective glazing dielectric multilayer structures
}

\author{
Venkatesh Yepuri $^{1,2}$, R. S. Dubey ${ }^{1, *}$, Brijesh Kumar ${ }^{2}$ \\ ${ }^{1}$ Department of Nanotechnology, Swarnandhra College of Engineering and Technology, \\ Seetharampuram, Narsapur (A.P.), India \\ ${ }^{2}$ Amity Institiute of Nanotechnology, Amity University, Gurgaon, (Haryana), India \\ *rag_pcw@yahoo.co.in
}

DOI 10.17586/2220-8054-2020-11-4-488-492

\begin{abstract}
We report the fabrication of three- and five-layered based $\mathrm{TiO}_{2} / \mathrm{SiO}_{2}$ dielectric structures as the back-end reflector application in thin film silicon solar cells. These dielectric structures are prepared by the combined sol-gel and spin-coating techniques. X-ray diffraction (XRD) analysis of both the three- and five-layered based structures confirmed the anatase phase of $\mathrm{TiO}_{2}$ with its dominant peak at $2 \theta=25^{\circ}$. Field-emission scanning electron microscopy (FESEM) study demonstrated the formation of three and five alternate layers of $\mathrm{TiO}_{2}$ and $\mathrm{SiO}_{2}$ films. Comparatively, five-layered based reflector yielded the maximum (100\%) reflectance in the near-infrared (NIR) wavelength region as evidenced by the UV-Vis spectroscopy investigation.
\end{abstract}

Keywords: sol-gel method, thin films, bragg reflectors, dielectric materials.

Received: 13 May 2020

Revised: 8 June 2020, 12 July 2020

\section{Introduction}

A Bragg reflector is an optical component which is nothing but the multilayer structure of two alternating materials of distinct refractive index. This optical device has got various applications as in listed in Fig. 1. These includes as the back-end reflector in solar cells, clads in optical waveguiding, as reflector in light-emitting devices, light splitter in photonic devices and their smart applications in new-generation fabrics, heat-resistance smart windows, and windshielding in automobiles [1-3].

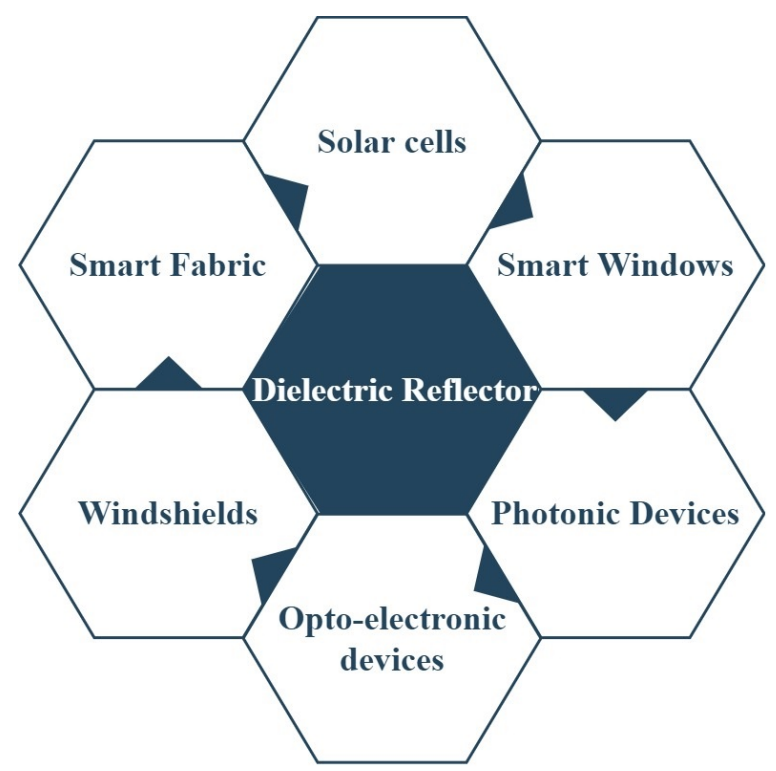

FIG. 1. Applications of dielectric reflectors

In thin film solar cells, the longer wavelength light is unabsorbed through the thin absorbing region and transmitted to the bottom-end [4]. Therefore, harvesting of light is very important in such thin film solar cells so that unabsorbed light can be reutilized. In this view, such reflectors are promising for the enhancement of light absorption in the 
thin absorbing layer and hence, conversion efficiency. Other than dielectric materials such as zinc oxide, zirconium oxide, etc., the $\mathrm{TiO}_{2}$ and $\mathrm{SiO}_{2}$ are the best opted dielectric materials due to their high refractive index contrast and non-hazardous during the processing by the sol-gel method. These materials have also been demanded for their potential applications such as anti-reflection coating, optical waveguides, photonic crystals etc. [5]. Sol-gel spin coating approach needs optimization of the process to attain the good step coverage, uniformity and crack free films [6]. The properties of $\mathrm{TiO}_{2} / \mathrm{SiO}_{2}$ layered based multilayer structure can be tuned for the specific applications, i.e., as the UV, visible and IR filters including lasers. Several investigations have been reported on the fabrication of reflective and anti-reflective coatings [7-14]. Calvo et al. introduced a synthetic route in fabricating Bragg mirrors with $\mathrm{TiO}_{2}$ thin-films by adopting the sol-gel spin coating [15]. He prepared the visible reflector with six layers of $\mathrm{TiO}_{2}-\mathrm{TiO}_{2}$ with periodic variation of refractive index and controlled porosity. The reflector showed reflectance below $100 \%$ in the visible spectrum and further, suggested the preparation of Bragg reflectors by tuning the precursor solution. Hinczewski et al. presented the preparation of optical filters based on $\mathrm{SiO}_{2}$ and $\mathrm{TiO}_{2}$ multi-layers by adopting the sol-gel spin coating technique [16]. The prepared structure was composed of nine alternate layers of $\mathrm{TiO}_{2} / \mathrm{SiO}_{2} \mathrm{which}$ endorsed $90 \%$ reflectivity in near-UV region with $90 \%$. The experimental results were also in good agreement with the theoretical investigations. Nagayoshi et al. prepared and studied the dielectric structure fabricated by using $\mathrm{TiO}_{2}$ nanoparticles mixed in $\mathrm{SiO}_{2}$ solution [17]. The spin coated films evidenced good reflectance (90\%) in the nearinfrared region. These studies were explored by varying the number of dielectric layers, optical thickness, and the choice of coating techniques i.e. spin or dip coating. Sol-gel spin coating is an inexpensive and simple process based technique. Under the atmospheric conditions one can maintain the good homogeneity of the coating. To attain this, annealing temperature and the molar ratio of the precursors are the essential factors.

This paper mainly deals with the fabrication of three and five layered based dielectric structures of $\mathrm{TiO}_{2}$ and $\mathrm{SiO}_{2}$ film which serves as distributed Bragg reflector (DBR). The periodic arrangement of three- and five-consecutive layers of $\mathrm{TiO}_{2}$ and $\mathrm{SiO}_{2}$ films showed as much as $74 \%$ and $100 \%$ reflectance in the NIR region respectively. Section 2 presents the experimental process for fabricating the dielectric reflectors. The investigations are discussed in the Section 3 and Section 4 concludes the work.

\section{Experimental process}

Titanium Isopropoxide (TTIP) and Tetra Ethyl Ortho Silicate (TEOS) precursors procured by Sigma-Aldrich were used as the Ti and Si sources. De-ionized and ethanol procured by Changshu Hongsheng Fine Chemicals were used as the solvent while hydrochloric acid supplied by Fischer Scientific as the chelating agent. All the reagents were of analytical grade and used without any further purification. The preparation of dielectric reflectors is presented in the typical flow chart as shown in Fig. 2.

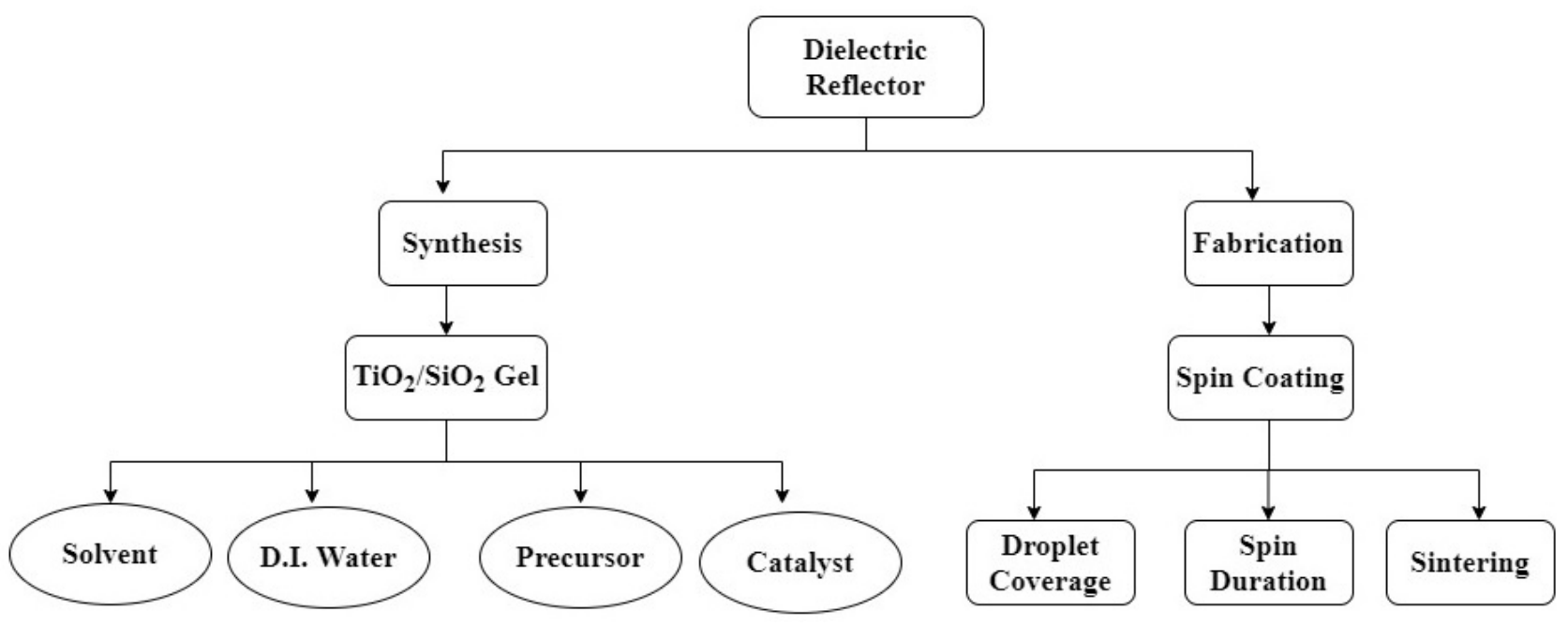

FIG. 2. Flow chart of synthesis and fabrication of dielectric reflector

To prepare the gels of $\mathrm{TiO}_{2}$ and $\mathrm{SiO}_{2}$, at first $20 \mathrm{ml}$ ethanol was added in $1 \mathrm{ml} \mathrm{DI}$ water and kept for $5 \mathrm{~min}$ stirring. Afterwards, $1 \mathrm{ml}$ precursor TTIP/TEOS drop-wise was added under vigorous stirring while maintaining 2 min interval in order to prepare the $\mathrm{TiO}_{2} / \mathrm{SiO}_{2}$ solution. Finally $0.2 \mathrm{ml} \mathrm{HCl}$ was added to the above solutions in order to promote the rate of reaction and kept for continuous stirring for two hr. Later, both the solutions were aged for 24 hours to 


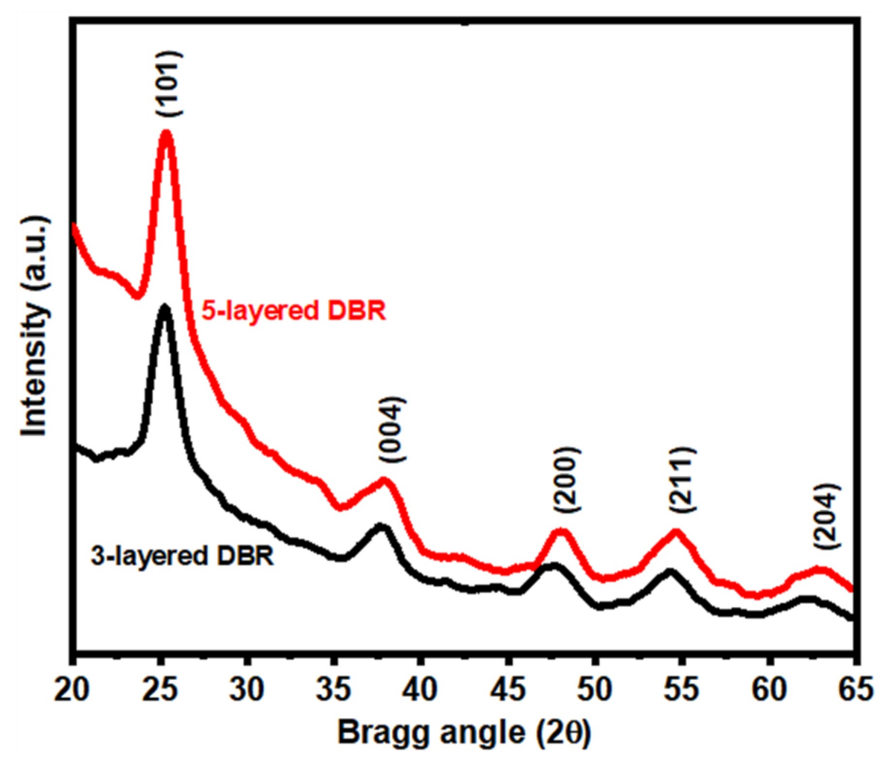

FIG. 3. XRD pattern of three and five-layered based DBR

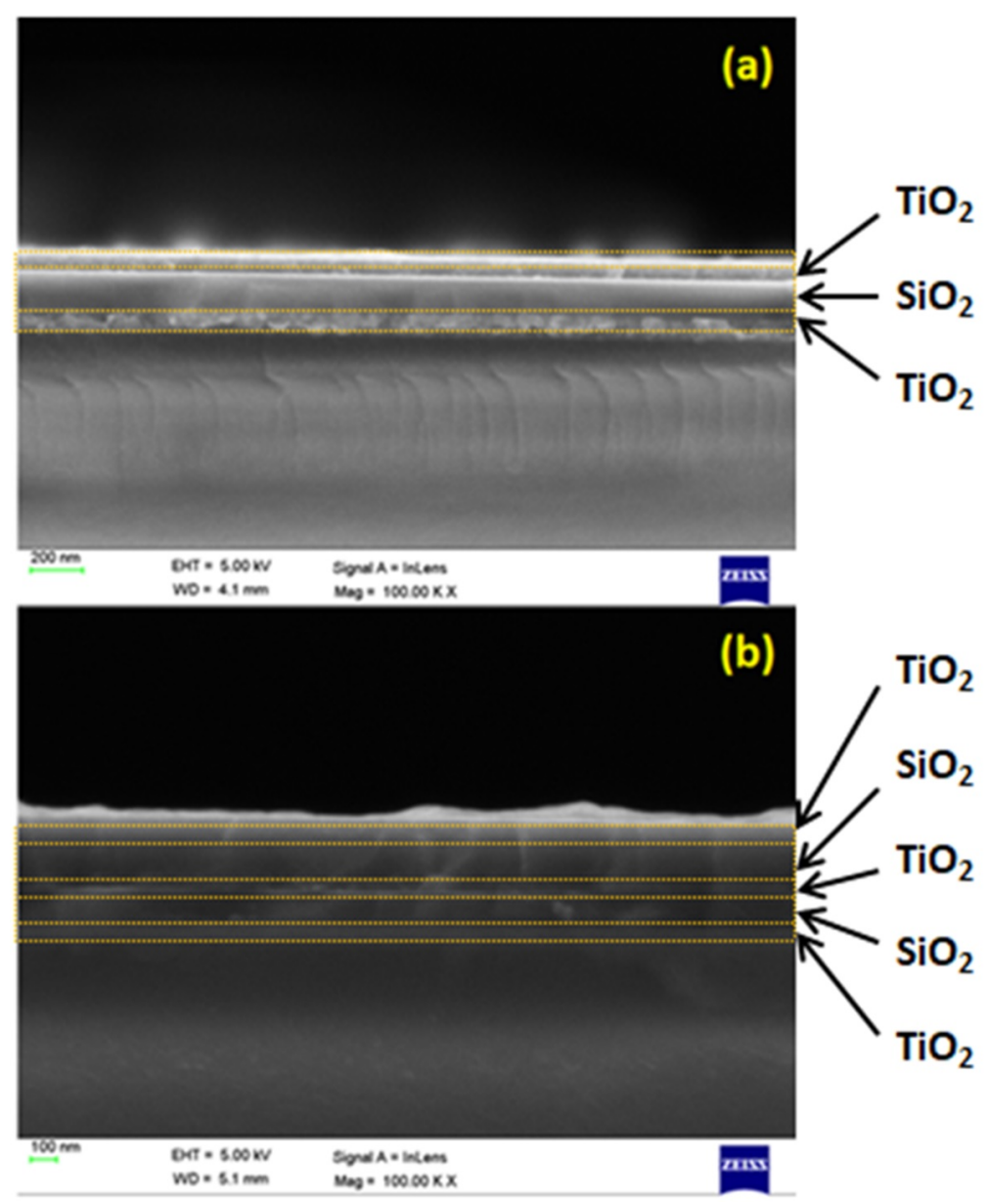

FIG. 4. (a)Cross-section FESEM images of three-layered based DBRs. (b)Cross-section FESEM images of five-layered based DBRs 
get the enough viscous and transparent gels. For the preparing the multilayer structures of $\mathrm{TiO}_{2}$ and $\mathrm{SiO}_{2}$ films, the glass substrates were thoroughly cleaned with the soap solution and sonicated in ethanol for 30 min. Further, after rinsing in water and drying, alternate layers were deposited by the spin coating process at 3000 RPM speed for 30 sec. After deposition of each film, these were dried in the hot air oven at temperature $100^{\circ} \mathrm{C}$ for $30 \mathrm{~min}$, in order to remove the volatile solvents. The as-prepared $\mathrm{TiO}_{2}$ and $\mathrm{SiO}_{2}$ films were sintered at temperature $500^{\circ} \mathrm{C}$ and $300^{\circ} \mathrm{C}$ for $1 \mathrm{hr}$ to eliminate the organic compounds and to form the crystalline structure. Further, the fabricated multilayer structures were examined by using XRD, FESEM and UV-Vis spectroscopy.

\section{Results and discussion}

XRD study was carried out to investigate the crystallization phase presence in the spin coated three and fivelayered based structures. Fig. 3 depicts the XRD pattern which endorses the anatase phase of $\mathrm{TiO}_{2}$.

The diffraction peaks located at $2 \theta=25^{\circ}, 37^{\circ}, 48^{\circ}, 55^{\circ}$ and $62^{\circ}$ are indexed corresponding to the planes (101), (004), (200), (211), and (204) respectively of anatase- $\mathrm{TiO}_{2}$ [17]. Our XRD results coincide with the JCPDS File No. 21-1272. One can notice the broadening of a Bragg peak located at $2 \theta=25^{\circ}$ ascribed to the plane (101) of $\mathrm{TiO}_{2}$, which usually indicates the existence of amorphous phase of $\mathrm{SiO}_{2}$. In addition, it is observed that the sequential annealing of each film did not the affect the crystallinity of the multilayer structures.

Figure 4(a,b) shows the cross-section FESEM images of three and five-layered based $\mathrm{TiO}_{2} / \mathrm{SiO}_{2}$ reflectors. The brighter and lighter layers shown in cross-section FESEM images indicate the deposition of $\mathrm{TiO}_{2}$ and $\mathrm{SiO}_{2}$ film respectively. The estimated thicknesses of eachlayer from bottom to top were $71 \mathrm{~nm}, 127 \mathrm{~nm}$ and $53 \mathrm{~nm}$, and $56 \mathrm{~nm}$, $97 \mathrm{~nm}, 59 \mathrm{~nm}, 135 \mathrm{~nm}$ and $56 \mathrm{~nm}$ corresponding to three- and five-layered based $\mathrm{TiO}_{2} / \mathrm{SiO}_{2}$ reflectors. Here, we can observe the periodic structure of titania and silica films with their high and low refractive indices.

Figure 5 depicts the reflectance spectra of three- and five-layered based reflectors. The three-layered reflector showed as much as $70 \%$ reflectance in the wavelength range from 500-1100 nm with its center wavelength $745 \mathrm{~nm}$.

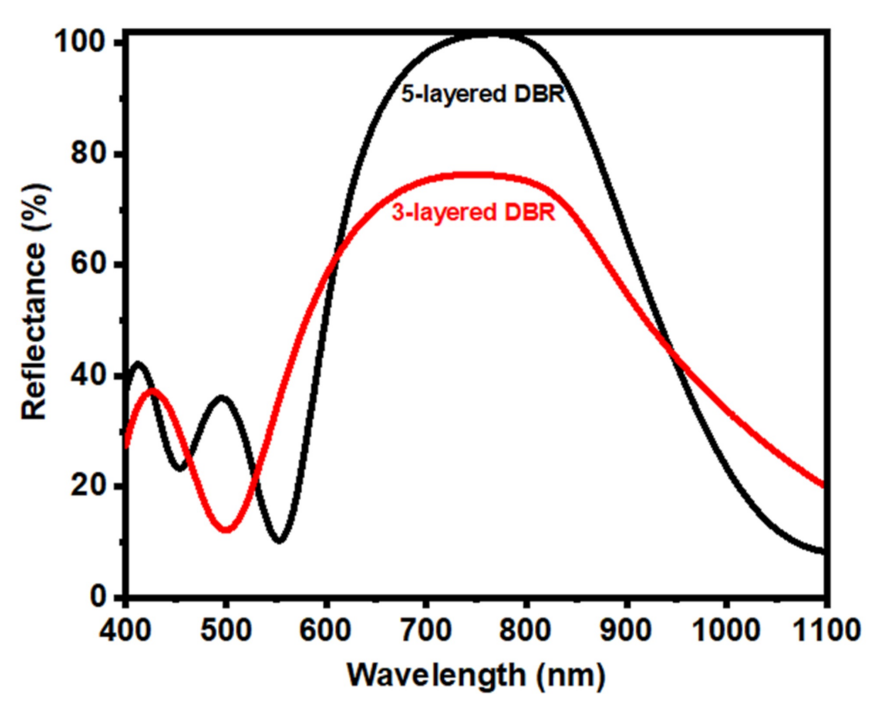

FIG. 5. Reflectance spectra of three- and five-layered based DBRs

Further, the increased layers of $\mathrm{TiO}_{2}$ and $\mathrm{SiO}_{2}$ films i.e. five-layered structure demonstrated the $100 \%$ reflectance with its center wavelength $764 \mathrm{~nm}$. Remarkably, both the reflectors dominated their reflectance bands in the nearinfrared region. Finally, we could attain maximum $100 \%$ reflectance with the use of only five layers of $\mathrm{TiO}_{2}$ and $\mathrm{SiO}_{2}$ films by depositing the films using spin coating process.

\section{Conclusion}

We have prepared the dielectric reflectors of $\mathrm{TiO}_{2} / \mathrm{SiO}_{2}$ films on glass substrates and studied the structural and optical properties. XRD results endorsed the presence of anatase- $\mathrm{TiO}_{2}$ phase in both the samples of three- and fivelayered structures of $\mathrm{TiO}_{2}$ and $\mathrm{SiO}_{2}$ films. Cross-section FESEM studies revealed the formation of alternate layers of $\mathrm{TiO}_{2}$ and $\mathrm{SiO}_{2}$. Finally, both the reflectors characterized to study the light behavior. As compared to three-layered reflector, the five-layered one showed the maximum reflectance i.e., $100 \%$ in the broad wavelength range with its 
center wavelength $764 \mathrm{~nm}$. This investigation is useful to tune the reflectivity in the desired wavelength range by adopting a simple and cost-effective fabrication technique.

\section{Acknowledgement}

We acknowledge the support provided by the UGC-DAE CSR, Indore (India) for the XRD measurements.

\section{References}

[1] Isabella O., Dobrovolskiy S., Kroon G., Zeman M. Design and application of dielectric distributed Bragg back reflector in thin-film silicon solar cells. J. Non-Cryst. Solids, 2012, 358(17), P. 2295-2298.

[2] Fu A., Gao H., Petrov P., Yang P. Widely tunable distributed Bragg reflectors integrated into nanowire waveguides. Nano Lett., 2015, 15(10), P. 6909-13.

[3] Lee S.M., Gong S.H., Kang J.H., Ebaid M., Ryu S.W., Cho Y.H. Optically pumped GaN vertical cavity surface emitting laser with high index-contrast nanoporous distributed Bragg reflector. Opt. Express, 2015, 23(9), P. 1687-1689.

[4] Dubey R.S., Ganesan V. Fabrication and characterization of $\mathrm{TiO}_{2} / \mathrm{SiO}_{2}$ based Bragg reflectors for light trapping applications. Results Phys., 2017, 7, P. 2271-2276.

[5] Jeong S.H., Jae K.K., Bong S.K., Seok H.S., Byung T.L. Optical application and characterization of $\mathrm{SiO}_{2}$ and TiO 2 films prepared using a reactive RF Magnetron sputtering. Vacuum, 2004, 76(4), P. 507-515.

[6] Rabaste S. Sol gel fabrication of thick multilayers applied to Bragg reflectors and microcavities. Thin Solid Films, 2002, 416(1-2), P. 242-247.

[7] Zhang Q., Wang J., Wu G., Shen J., Buddhudu S. Interference coating by hydrophobic aerogel-like SiO 2 thin films. Mater. Chem. Phys, 2001, 72(1), P. 56-59.

[8] Mennig M., Oliveira P.W., Schmidt H. Interference coatings on glass based on photopolymerizable nanomer material. Thin Solid Films, 1999, 351(1-2), P. 99-102.

[9] San Vicente G., Morales A., Gutierrez M.T. Preparation and Characterization of Sol-Gel TiO 2 Antireflective Coatings for Silicon. Thin Solid Film, 2001, 391(1), P. 133-137.

[10] Hammarberg E., Roos A. Antireflection treatment of low-emitting glazings for energy efficient windows with high visible transmittance. Thin Solid Films, 2003, 442(1-2), P. 222-226.

[11] Bautista M.C., Morales A. Silica antireflective films on glass produced by the sol-gel method. Sol. Energy Mater. Sol. Cells, 2003, 80(2), P. 217-225.

[12] Vong M.S.W., Sermon P.A. Observing the breathing of silica sol-gel-derived anti-reflection optical coatings. Thin Solid Films, 1997, 293(1-2), P. 185-195.

[13] Nostell P., Roos A., Karlsson B. Optical and mechanical properties of sol-gel antireflective films for solar energy applications. Thin Solid Films, 1999, 351(1-2), P. 170-175.

[14] San Vicente G., Morales A., Gutierrez M.T. Sol-gel TiO 2 antireflective films for textured monocrystalline silicon solar cells. Thin Solid Films, 2002, 403-404, P. 335-338.

[15] Calvo M.E. Photoconducting Bragg Mirrors based on $\mathrm{TiO}_{2}$ Nanoparticle. Adv. Funct. Mat., 2008, 18(18), P. $2708-2715$.

[16] Saygin Hinczewski D., Hinczewski M., Tepehan F.Z., Tepehan G.G. Optical filters from $\mathrm{SiO}_{2}$ and TiO 2 multi-layers using sol-gel spin coating method. Sol. Energ. Mat. Sol. C, 2005, 87(1-4), P. 181-196.

[17] Nagayoshi H., Takuya Murooka. $\mathrm{TiO}_{2}$ nanoparticle/SiO 2 composite back reflector for solar cells. Energy Procedia, $2015,77, \mathrm{P} .242-247$.

[18] Nandanwar R., Singh P., Syed F.F., Haque Z.F. Preparation of $\mathrm{TiO}_{2} / \mathrm{SiO}_{2}$ Nanocomposite with Non-ionic Surfactants via Sol-gel Process and their Photocatalytic Study. Orient. J. Chem., 2014, 30(4), P. 1577-1584. 